\title{
Retrosigmoid approach for resection of petrous apex meningioma
}

\author{
Daniel G. de Souza, M.D., Leo F. S. Ditzel Filho, M.D., Girma Makonnen, M.D., \\ Matteo Zoli, M.D., Cristian Naudy, M.D., Jun Muto, M.D., \\ and Daniel M. Prevedello, M.D.
}

Department of Neurological Surgery, The Ohio State University, Columbus, Ohio

We present the case of a 50-year-old female with a 1-year history of right-side facial numbness, as well as an electric shock-like sensation on the right-side of the face and tongue. She was previously diagnosed with vertigo and trigeminal neuralgia. MRI was obtained showing a large right cerebellopontine angle mass. A retrosigmoid approach was performed and total removal was achieved after dissection of tumor from brainstem and cranial nerves IV, V, VI, VII and VIII. Pathology confirmed the diagnosis of a meningioma (WHO Grade I). The patient was discharged neurologically intact on the third postoperative day free of complications.

The video can be found here: http://youtu.be/-tR0FtMiUDg.

(http://thejns.org/doi/abs/10.3171/2014.V1.FOCUS13456)

KeY WordS • retrosigmoid approach • meningioma • petrous apex • video

Manuscript submitted October 1, 2013.

Accepted November 19, 2013.

Please include this information when citing this paper: DOI: 10.3171/2014.V1.FOCUS13456.

Address correspondence to: Dr. Daniel M. Prevedello, The Ohio State University, Department of Neurosurgery, N1011 Doan Hall, 410 W 10th Avenue, Columbus, Ohio 43016. email: daniel. prevedello@osumc.edu. 